\title{
OS ESPAÇOS GEOGRÁFICOS MARÍTIMOS DE ATENAS AO MAR NEGRO
}

\author{
Maria Regina Cândido ${ }^{1}$
}

\begin{abstract}
Resumo
Através do espaço geográfico marítimo que os gregos efetivaram o processo de migração para as diferentes regiões banhadas pelo mar Egeu, Mediterrâneo e Mar Negro, fundaram novas poleis, efetivaram uma identidade compartilhada, transferiram seus cultos e deuses, produziram artefatos de cerâmica e metais formando a rede de conectividade marítima através de emporium e apoikias.
\end{abstract}

\section{Palavras-chave}

Conectividade; Geografia; Mar Negro.

\begin{abstract}
Through the maritime geographical space that the Greeks made the process of migration to the different regions bathed by sea throughout the Aegean, Mediterranean and Black Sea, founded new poleis, carried out a shared identity, transferred their cults and gods, produced ceramic and metal artifacts forming the net Of maritime connectivity through emporium and apoikias.
\end{abstract}

Keywords

Connectivity; Geography; Black Sea.

\footnotetext{
1 Professora Doutora, Universidade Estadual do Rio de Janeiro, Rio de Janeiro, Brasil. E-mail: $\underline{\text { medeiacandido@gmail.com }}$
} 
Refletir sobre o tempo, passado, presente e futuro tornou-se uma atividade essencial das sociedades humanas e matriz da construção da História, na qual o tempo tornou-se objeto de conhecimento, de analise da transformação, de permanentes mudanças aceleradas em que vivemos, resultando com que tudo que é solido se desmanche no ar (Guarinello, 2008: 14). Neste ensaio nos propomos a trazer ao debate as considerações sobre os espaços geográficos marítimos ${ }^{2}$ do Mediterrâneo e Mar Negro no período arcaico e clássico dos gregos. Considera-se o espaço marítimo como agente propulsor de ritmos temporais próprios ao qual se permite afirmar que não são os espaços geográficos que fazem a História e sim os homens que são senhores e inventores desses espaços (Braudel, 1966: 206).

Durante um longo período na construção da história ocidental, o Mar Egeu e Mediterrâneo permitiram o contato e a interação entre culturas de diferentes etnias, difundiram crenças e tradição e têm sido objeto de idealizações para mundo ocidental. A estabilidade da natureza marítima favoreceu o comércio de cabotagem de diferentes produtos como as pedras das ilhas Cíclades, o mármore da Itália e do Egeu, o couro de Chipre e da Sardenha, o ferro da Ibéria, o ouro da região de Tasos e madeira da Trácia, a prata de Andaluzia assim como os cereais da planície da Tunísia, na região do Pó, na Campânia e Sicília. Produtos e mercadorias que favoreceram a aproximação de culturas, crenças e tradições distintas entre si em torno do Mediterrâneo, ação que se estendeu ao Mar Negro.

Os espaços geográficos marítimos comunicam entre si através das trocas comerciais e mercantis, mas também permite a circulação de pessoas. A verdadeira riqueza do Mediterrâneo e Mar Negro reside precisamente nesta pulsão proporcionada pelas relações intensas que se desenvolveram cujo resultado se materializou em todos os domínios da vida social, religiosa e econômica como a realização de casamentos mistos, cultura hibrida, novos cultos e ritos religiosos.

Partimos do princípio que a sociedade dos gregos pode ser pensada em termos de conectividade próximas e distantes através da abordagem da Social Network Theory, traduzida por nós como Teoria da Conectividade Social. Embora o conceito de network pertença a área de conhecimento tecnológico, consideramos que a noção detém a capacidade de aplicação

\footnotetext{
2 O conceito integra a tese de Doutorado do Prof. Alair Figueiredo Duarte intitulada Comparando fronteiras terrestres e fronteiras marítimas: a participação política e social dos thetas na polis atenienses do século V a.C. Defendida em 03/2017 na PPGHC/UFRJ sob a orientação da Profa. Dra. Maria Regina Candido (NEA/PPGH/UERJ; PPGHC/UFRJ).
} 
teórica junto a História Antiga como nos aponta Ch. Constantakopolou, The Dance of the Islands: Insularity, Networks, the Athenian Empire and the Aegean World (2007), Irad Malkin e Ch. Constantakopolou, Greek and Roman Network in the Mediterranean.(2009) e Irad Malkin. A Small Greek World. Network in the ancient Mediterranean.(2011). Os autores partem da perspectiva de que a conectividade marítima fomentou a mobilização de atenienses, gregos e não gregos pelo Mar Mediterrâneo em direção ao Mar Negro desde o período arcaico. Através do espaço geográfico marítimo que os gregos efetivaram o processo de migração para as diferentes regiões banhadas pelo Egeu, Mediterrâneo e Mar Negro, fundaram novas poleis, efetivaram uma identidade compartilhada, transferiram seus cultos e deuses, produziram artefatos de cerâmica e metais formando a rede de conectividade maritima através de emporium, cleuruquias e apoikias.

Argumentamos que as regiões banhadas pelo Mediterrâneo estenderam seus contatos em direção ao Oriente Próximo, Vale do Nilo, a África e a Mesopotâmia alcançando o Mar Negro. Nestas regiões, os gregos efetivam o estabelecimento da liderança unipolar ${ }^{3}$ que se estendeu aos romanos cujos contatos culturais contribuíram para a formação da civilidade mediterrânica das quais acreditamos que somos herdeiros. Partimos do princípio que o espaço geográfico marítimo do Mediterrâneo detém uma vasta historiografia, no entanto, o processo de conectividade dos gregos em diferentes regiões do mundo antigo detém a peculiaridade de ser a região do Mar Negro a menos conhecida do universo acadêmico do Ocidente e com ausência de análise, realizada por nós, da historiografia latino-americana.

F.Braudel sugere que sobre o imenso passado da humanidade, o mar tornou-se o seu mais belo testemunho e na obra The Mediterranean afirma que o Mar Mediterrâneo constitui-se como uma unidade que vai da Antiguidade a Idade Média. A afirmação faz parte do "paradigma do Mediterrâneo" ao qual considera a região do mar como fator de unidade cultural, resultando na abordagem do pan-mediterranismo. A tese foi refutada na obra The Corrupcion Sea cujos autores argumentavam que a fragmentação da paisagem da região, diante da sua diversidade física e étnica jamais conseguiu formular uma unidade cultural (Purcell, 2000: 09). Nicholas Purcell afirma que a região integra três formas de abordagens, a saber: os interacionistas que analisam a região a partir de geografia física na qual o mar torna-se via de contato e de comunicação;

\footnotetext{
${ }^{3} \mathrm{O}$ conceito integra a publicação do livro Atenas, liderança unipolar no Mar Egeu (480 411 a.C.) de 2016, pesquisa fez parte do projeto Prociência 2010-2014, financiado pela FAPERJ/UERJ e de minha autoria.
} 
os ecologizing que enfatizam as relações do homem e o meio ambiente resultando na análise das culturais estabelecidas no interior da região e o terceiro grupo que unifica as duas anteriores sob a abordagem da microecologia e criaram a noção de conectividade através do mar (Purcell, 2000:10).

Os historiadores gregos como Tucídides e Heródoto trazem em seu discurso a conceituação do mar definido como talassocracia resultado do sucesso da liderança unipolar dos atenienses, estabelecida desde o Mar Egeu, passando pelo Mediterrâneo e se estendendo ao Mar Negro. As atividades mercantis e comerciais em Atenas receberam estímulos pecuniários sem precedentes no $\mathrm{V}$ século, promovidas pela atividade marítima no sentido militar e mercantil. Heródoto nos relata que o estratego Temístocles persuadiu cada ateniense a renunciar a sua parte dos recursos provenientes das minas de Laurion e aplicar na construção de duzentas naus para a defesa da polis. O historiador acrescenta que a guerra tornara-se a salvação da Hélade, pois compeliu os atenienses a exercerem a função de marinheiros (Heródoto, VII:144); o tema foi relatado por Tucídides ( I:74) e Plutarco: Temístocles (v. 4).

A documentação nos permite afirmar que foram as trieres de Temístocles que salvaram Atenas e a Grécia de fracassar perante os persas e as fizeram triunfar em Salamina. Os pesquisadores acrescentam que graças às ações políticas de Péricles, as trieres asseguraram a hegemonia marítima de Atenas e sua prosperidade. $\mathrm{O}$ resultado promoveu a emergência de setores urbanos que passaram a pressionar por uma política externa ativa representando não apenas o interesse de comerciantes no mercado, mas um reconhecimento de validade da relação entre a remuneração militar e a prosperidade econômica (Humphreys, 1978: 7). Claude Mossé acrescenta que a frota naval e a criação da Liga de Delos por Temístocles e Aristides definem-se como os principais instrumentos que impulsionaram o estabelecimento do imperialismo ateniense (Mossé, 1993: 33). Aristóteles deixa transparecer que, assim como Temístocles, a inserção do quarto segmento social sediado no espaço urbano tornou-se uma prática também com Péricles ao adotar a política de poderio naval inserindo as classes mais baixas assumindo cada vez mais a liderança na política (Aristóteles, Constituição de Atenas, XVII), ou seja, os cidadãos integrantes da frota ateniense em defesa da polis buscavam a sua participação ativa junto à administração dos negócios públicos da polis, graças ao processo de expansão marítima fomentada por Atenas. A ação política do chamado império ateniense transcende a estrutura da comunidade políade ao construir áreas de influência nas regiões banhadas pelo Egeu. $\mathrm{O}$ estabelecimento da Liga de 
Delos e os recursos provenientes das aliadas ajudaram no pagamento dos misthoi e na manutenção da participação dos emergentes dos setores urbanos na democracia (Candido, 2016:115).

Atenas reconhece que a expansão da hegemonia visando o controle marítimo somente seria eficaz através do estabelecimento de redes de conectividades comercial, mercantil e de pessoas. A materialidade da talassocracia dos atenienses tornou-se perceptível através dos vasos de cerâmica ática que criaram um estilo técnico singular na forma de vasos áticos de figuras negras, bilingual e de figuras vermelhas, cujo resultado impulsionou a dinâmica de trocas comerciais e mercantis de exportação de Atenas para diferentes regiões do Egeu, Mediterrâneo ao Mar Negro. Tal fato fomentou a emergência do segmento social dos olighoi, os emergentes ou novos ricos, envolvido nas atividades comerciais de produção de cerâmica ática e os mercadores responsáveis pela exportação de vasos áticos com vinho, azeite e grãos. O Velho Oligarca ratificou a atividade no $\mathrm{V}$ sec. Ao citar que os atenienses, em razão do dominio marítimo, misturaram-se com outras etnias e descobriram produtos de consumo variados...qualquer que seja o produto e onde quer que esteja, Sicilia, Italia, Chipre, Egito, Lidia e no Mar Negro tudo vem para o mesmo ponto do Porto do Pireu em virtude do poder naval (Constituição de Atenas, II:07). A citação do Velho Oligarca deixa transparecer que Atenas exercia, de maneira eficaz, a talassocracia e a liderança unipolar nos Mar Egeu e que os gregos tinham noção da existência e acesso ao Mar Negro. Daniela Dueck afirma que os gregos já estavam em processo de expansão pelo Mediterrâneo no periodo arcaico devido ao domínio da navegação pelas encostas e do conhecimento de regiões limítrofes. Entretanto, no VII século, os gregos se aventuram em direção ao Mar Negro (Dueck, 2012: 2).

O domínio marítimo requer conhecimentos náuticos e domínio da astronomia para a direção e os gregos tinham conhecimento da representação imagética do mundo conhecido como nos deixa transparecer o fragmento DK12A1, de Diogenes de Laertes, no qual cita que Anaximandro de Mileto havia sido considerado como o primeiro logógrafo a usar um gnómon entre os helenos, conhecimento apreendido a partir de sua estada no Egito e na Babilônia (Heródoto, II:109). O instrumento permitiu que Anaximandro assinalasse a circunferência da terra, definisse os solstícios e equinócios, demarcasse a divisão do dia em 12 partes e traçasse um contorno da terra e do mar (Kirk,1994: 99). O instrumento impulsionou o saber sobre a geografia e se manteve na memória dos gregos como nos aponta o geografo Agathemerus, contemporâneo de Estrabão, ao citar, a saber: 
Anaximandro de Mileto, discípulo de Thales, foi o primeiro que ousou desenhar o mundo habitado/oikoumenos numa tábua; depois dele, Hecateu de Mileto, homem muito viajado, aperfeiçoou o mapa, de forma que a obra se tornou uma fonte de admiração (Agathemerus, I,1 apud Kirk, 1994: 103).

A citação menciona o geógrafo Hecateu de Mileto como alguém que aperfeiçoou o mapa do mundo habitado/oikoumenes. O pesquisador Katzuso Koike considera que Hecateu, conhecedor da cultura ancestral poética, tinha total noção de que muitos dos dados geográficos fornecidos por Homero detinha alguma veracidade. Afirma que Hecateu foi capaz de realizar viagens por si mesmo e de averiguar se as informações épicas eram ou não verossímeis. Se por um lado era praticamente impossível localizar as ilhas de Circe e Calipso, ou a terra dos Ciclopes e dos Lotófagos, que atendiam sobremaneira aos intuitos épicos da viagem de Ulisses, por outro lado, muitos aspectos culturais e antropológicos serviram de base para a descrição periegética de Hecateu. Por exemplo, o autor da Odisseia refere que os Cíclopes eram basicamente pastores rudes, que viviam em terras férteis, mas não plantavam nem comiam pão

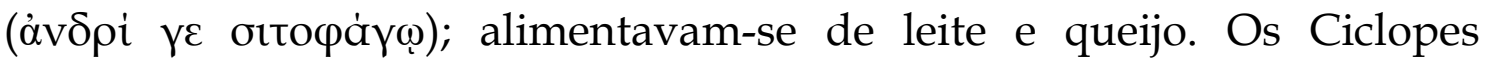
possuem várias marcas de selvageria e ausência de cultura, que o poeta alinha, como por exemplo, eram homens grandes, de um olho só, gigantes com força descomunal, que viviam sem fazer leis e sem praticar agricultura (Odisseia, IX 292-293)., não tinham cidades, nem construíam barco e praticavam a antropofagia (Katzuso, 2013: 81). Katzuso Koike afirma que, Hecateu fará as descrições de muitas regiões e ainda vai relatar que os Egípcios eram artóphagoi, comedores de pão, considerando que artos é o termo comum para "pão" em grego antigo. No entanto, Hecateu menciona que os habitantes de Gérasa, cidade da Líbia, são comedores de pão, o termo usado é sitóphagoi, o mesmo que aparece em Homero, uma palavra composta que utiliza como raíz sítos, (trigo, farinha, grão ou pão) para denominar aqueles que vivem do que plantam, nesse caso, dos grãos (Katzuso, 2013: 82).

Heródoto no período clássico, empreende viagens marítimas em torno do mundo habitado/oikoumenos, através de uma abordagem antropológica, nos traz a especificidade de algumas culturas, semelhante as mencionadas por Homero e Hecateu, vejamos a citação:

os andrófagos têm os costumes mais selvagens entre todos os homens, pois, não observam a justiça e nem adotam qualquer lei. Eles são nômades e se vestem à maneira dos citas, tem uma língua própria, e entre todos os povos são os únicos a comer carne humana. (Heródoto, IV,106)

Em seguida, Heródoto, em sua periegisis marítima pelo mundo, menciona o encontro com a cultura dos Lotófagos da costa Líbia, a saber: 
Existe uma ponta de terra penetrando pelo mar diante do território dos gindanes, nela habitam os lotófagos que vivem comendo exclusivamente o fruto do lótus. Esses frutos e do tamanho da baga da aroeira, e tem um gosto açucarado comparável ao das tâmaras, os lotófagos fazem também vinho desses frutos (Heródoto, IV,177)

Heródoto confirma a sua viagem marítima ao menciona que os povos enumerados acima são os líbios nômades habitantes da orla marítima (Heródoto, IV,181). As citações do "pai da História" nos permite afirmar que o seu livro História/investigação, na primeira metade do V século, deixa transparecer que transitou por diferentes regiões habitadas. As viagens a mundos estranhos e exóticos, aguçou o seu poder de observação sobre a região, levando-o a se aventurar na demarcação de um mapa geográfico, semelhantes aos construídos pela tradição jônica. Torna-se interessante observar que Heródoto teceu críticas ao fato de geógrafos como Anaximandro e Hecateu de Mileto, provenientes de cidade comercial e fundadora de colônias, terem traçado o continente asiático da mesma proporção que a região da Europa, vejamos a citação:

sorrio ao ver que até agora muitos foram os que desenharam o circuito da Terra... sem que nenhum deles tenha dado ao assunto uma explicação razoável.... representam o Oceano a correr ao redor da terra e desenham com compasso/gnomon o que resultam fazer a Ásia ser igual a Europa (Heródoto, IV: 36).

No mapa de Anaximandro de Mileto fica bem demarcado que o centro do mundo civilizado no periodo arcaico encontrava-se em torno do rio Nilo, região considerada como o berço da humanidade e que os egípcios legaram aos gregos o alfabeto e o gnomon (Couprie, 2003: 50). Os gregos já estavam familiarizados com a complexidade e o potencial saber das antigas culturas do Oriente Próximo, centro propulsor do mundo arcaico no qual as regiões gregas ocupavam uma posição periférica (Malkin, 2011: 8). No mapa de Anaximandro também fica demarcado a região do Mar Negro denominada de Mar Euxine/mar bom para estrangeiros, e o rio Fasis em Colquida, informação que nos indica que a região já era de conhecimento dos gregos no período arcaico.

Outro dado que nos chama a atenção está na divisão do orbis terrarum, do mundo habitado/oikoumenos composto pela Europa, Ásia e Líbia indicando possíveis migrações de diferentes etnias, alguns seriam familiares a Anaximandro proveniente de observações e viagens. Percebe-se que o local de cada grupo étnico mantem demarcação no mapa assim como as rotas de migração, áreas de comercio e assentamentos militar de guerreiros gregos (Couprie, 2003: 52). Heródoto parece ter analisado o mapa do mundo habitado proveniente de Mileto 
ao tecer a critica sobre aqueles que separaram e dividiram o mundo habitado em três partes, a saber:

Admiro-me, então, daqueles que separaram e dividiram o mundo em Líbia, Ásia e Europa; em verdade, a diferença entre essas três partes não é pequena, pois no sentido longitudinal a Europa se estende ao longo das duas outras partes juntas, e sua largura me parece incomparavelmente maior. Com efeito, nossos conhecimentos a respeito da Líbia evidenciam que ela totalmente cercada pelo mar, salvo as suas fronteiras com a Ásia...(Heródoto, IV: 42)

Através do uso do gnomon, o pré-socrático promoveu um processo revolucionário de abstração geográfica de representação do espaço do Mediterrâneo na qual incluía o Mar Negro. A delimitação das regiões pela cartografia de Anaximandro estabelecia uma inovadora maneira de ver o mundo, talvez na tentativa de materializar as navegações míticas cantadas nas poesias épicas dos aedos e rapsodos, narradores de Homero, que transitavam pela região do espaço marítimo conhecido pelos gregos.

O primeiro escrito de Hecateu, segundo Katzuso Koike, se encerra na produção de uma literatura de viagem que se desenvolveu no Mundo Grego em decorrência da colonização jônica no Mediterrâneo e pela confirmação do uso da própria escrita como técnica de produção intelectual. As viagens, como temática na literatura grega, fizeram parte de vários gêneros, como o épico da Ilíada e Odisseia, além das narrativas geográficas ou históricas, como Heródoto e depois, Pausânias. Homens viajados do século VI a.C., como por exemplo Eutímenes de Massália, Cílax de Carianda e o próprio Hecateu de Mileto, deixaram registradas as suas explorações em escritos que ficaram conhecidos em grego como Périploi e Periegeseis (Katzuso, 2013: 125). O verbo grego peripléo significa navegar ao redor ou circunavegar, expressa o sentido e a descrição de um itinerário marítimo, no qual o geografo fornecia informações geográficas de caminhos percorridos, bem como apontava as distâncias, a localização de portos, de apoikias, de grupos étnicos e dos pontos de referências para os viajantes náuticos .

O períodos gês contém a ideia mais antiga de representação da terra habitada e conhecida, então confeccionada sobre uma pínax, como os mapas construídos por Anaximandro e Hecateu. Devemos lembrar que períodos gês foi também o nome dado por Heródoto aos mapas dos "jônios" (Heródoto, IV, 36). A expressão, posteriormente, passou a indicar uma obra que descrevia esses mapas em seus pormenores, como vemos nos fragmentos de Hecateu. Foi usando o conceito de períodos gês que Aristóteles se referiu a obras de viagens, úteis aos governantes por tratarem dos "costumes dos povos" (Retórica, I, 1360a). O uso do termo períodos gês em Hecateu devia retratar especificamente a sua carta 
geográfica. O nome Periegesis parece ser tardio, não havendo registros de uso desse termo em períodos anteriores a Polemon de Ílion, do século IIIII a.C. Koike considera que Hecateu pode ter sido o primeiro a fazer uma descrição geo-etnográfica da oikoumenes, e que a partir de então, e sobretudo com Heródoto, o conceito passou a existir intimamente ligado ao gênero histórico (Katzuso, 2013: 126)

Consideramos que nomear um espaço percorrido significava acima de tudo, tomar posse desse espaço através da palavra. Esses geógrafos e navegadores nomearam os espaços geográficos marítimos por onde passaram de maneira recente, pois os nomes dos mares não constam nos poemas épicos da Ilíada e da Odisseia, fato que demonstra que navegavam por mares não nomeados e pouco conhecidos. Em relação a Hecateu de Mileto, tudo se passou de maneira diferente, os fragmentos da obra que chegou até nós, fornecem indícios que a ideia de atribuir nomes aos espaços geográficos marítimos fazia parte da construção de reconhecimento dos lugares navegados visando a elaboração do mapa relativo ao mundo habitado/oikoumenes. Para os geógrafos jônios, o Mediterrâneo era um mar fechado e nos confins da navegação, era possível encontrar o Mar Negro (Gras,1998: 33)

Podemos ratificar o conhecimento dos gregos sobre o Mar Negro através da citação de Heródoto que deixa transparecer não ter estado na região ao citar que a região do Ponto Euxinos é da todas as regiões aquela cuja população é mais ignorante, com efeito não podemos fazer menção a qualquer dos povos habitantes do interior do Ponto por seu saber, e não conhecemos qualquer homem culto nascido lá (Heródoto, IV: 46). Entretanto, o historiador menciona que na região havia os cólquidos, cujo território se estendia até o mar do Norte na qual desaguava o rio Fasis (Heródoto, IV, 37). Os jônios empreenderam o processo de migração para a região do Mar Negro no VIII século, fundaram várias poleis, apoikiai e emporia, vastamente divulgados por Anaximenes de Lampsaco (380-320 aC) que forneceu uma lista de nomes das colônias de mileto situadas no Mar Negro (Gras,1998: 59).

Os geógrafos conheciam a região como Ponto Euxino, o qual podemos defini-lo com mar hospitaleiro, porém, no período dos Argonautas era conhecido como lugar inóspito/axenos, devido as tempestades e os ataques da população considerada violenta e selvagem. $\mathrm{O}$ imaginário social da vizinhança selvagem permaneceu por um longo tempo, pois Estrabão menciona que os habitantes do Mar Negro imolavam os estrangeiros aos deuses, se alimentavam da sua carne e usavam os crânios das vítimas como taça (Estrabão,VII,3). Mesmo diante das dificuldades os gregos aportaram na região, os milésios controlaram a 
região devido a abundância de peixe, trigo, peles e metais. As poleis de Trapezona e Sinope detém a mais antiga data de fundação que segunda a documentação data de 756 aC (Gras,1998: 63).

O contemporâneo de Heródoto, o poeta Eurípides, menciona que Medeia provem da região de Colquida, região do Mar Negro, porém também não especifica de qual polis bárbara a princesa de Colquida seria proveniente tendo em vista que a região era composta de emporium e apoikias gregas. Fato que nos leva a trazer para o primeiro plano a região de Colquida, região considerada pelos gregos como integrante das poleis barbaras, mas, área de interesse pois a região detém abundância de terras férteis, de madeira, de grãos e de ouro.

O processo de migração ática para a região da Colquida situada no Mar Negro no período clássico foi narrada por Heródoto ao mencionar o contato cultural e a geografia da região cujo valor econômico centrava-se em torno do rio Fasis (Heródoto, III:93) , Péricles navegou diversas vezes pela região com uma frota naval a partir de 437/36a.C. visando ratificar a conectividade comercial e econômica da região da Atenas com os entrepostos comerciais estabelecidos junto aos cólquidos (Plutarco, Péricles:24), Xenofontes na obra Anábasis (IV,8.22) nos fornece dados sobre a urbanização em torno do Mar Negro, informações provenientes de sua estada na região que após uma longa jornada pelas montanhas, ele e a tropa chegam a Trapezona, uma colônia de Sinope no território de Colquida. Xenofonte nos informa que permaneceu na região dos cólquidos por trinta dias e que participaram de jogos atléticos da região. Ao final da estada realizou-se um ritual de hospitalidade com trocas de presente aonde se estabeleceu uma relação de philia com grupos de famílias áticas e de cólquidos assentados na região (Faudot, 2005: 108).

Consideramos que a materialidade da região em Atenas, ocorreu através de Eurípides ao trazer a memória dos atenienses e demais gregos a narrativa mítica do Velo de Ouro ratificada pelos artesão-ceramistas e nas entrelinhas da dramaturgia intitulada Medeia, representada no Teatro de Dionisos em 431 a.C.. A narrativa mítica traz a protagonista como uma mulher estrangeira proveniente da região bárbara de Colquida que migra para a Grécia trazida pelas mãos do jovem argonauta Jasão.

Para Anna M. Ckonia, a presença do ouro na região tem sido considerada como uma das forças motrizes que impulsionou o processo de navegação e migração dos gregos áticos para a região de Colquida. A região ficou conhecida na antiguidade como "região rica em ouro", e na modernidade ficou conhecida como "terra clássica do ouro" no qual a narrativa mítica de Jasão e o Velo de Ouro simbolizaram a riqueza aurífera e o interesse 
ático na região (Ckonia, 2002: 263). Entretanto, T.S.Noonan trouxe a perspectiva da exportações de grãos do Mar Negro para a Grécia, mencionada pela documentação antiga, ao considerar a região como "celeiro de Atenas" (Noonan, 1973: 231). David Braund considera que o Porto do Pireu tornou-se no período clássico uma área de acentuado poder e riqueza devido as intensas trocas comerciais e mercantis com o Mar Negro (Braund, 2007: 42).

Consideramos que a ideia de Mediterrâneo foi uma construção que se tornou sinônimo da atuação de gregos e romanos e matriz de análise para a formação do imperialismo cultural eurocêntrico. A historiografia com base em Heródoto e Eurípides definiu que a civilidade circulava pelo Mar Mediterrâneo e a barbárie pertencia aos residentes do Mar Negro. Quanto mais perto se estiver do Mar Mediterrâneo, mais próximo se esta da civilidade e da cultura, quanto mais distante e afastado, caminha-se em direção a periferia de povos bárbaros, espaço geográfico ao qual se deve evitar o contato e a circulação. Kostas Vlassopoulos afirma que a relação entre gregos e bárbaros faz parte de um amplo debate que parte da distinção geográfica entre o Ocidente versus Oriente. Os gregos detém a helenidade, a cultura, a sociabilidade e tornaram-se referência no Ocidente, inventaram a democracia, a liberdade de expressão, a ciência, a filosofia e a dramaturgia e o Oriente passou a ser a área de povos considerados bárbaros (Vlassopoulos, 2013: 02).

$\mathrm{Na}$ atualidade independente da relação binaria de oposição entre Ocidente versus Oriente, cristão versus mulçumanos e europeus versus bárbaros no campo intelectual e no universo acadêmico, os integrantes da Soviet Classical Studies mantem publicações em língua inglesa como a edição da obra Ruthenia Classica Aetatis Novae: A Collections of World by Russian scholars in Ancient Greek and Roman History ${ }^{4}$ (2013). Emergem as aproximações através da realização de congressos no qual apresentam o estado atual das questões relacionadas a região do Mar Negro como 6th International Congress on Black Sea Antiquities em Constanta, de 18 a 22/09/2017; Actes du IXe/1999 e Xe/2002 Symposium de Vani, Colquida; assim como o grupo de pesquisadores anglo-americanos, em parceria com helenistas russos e pesquisadores de universidades no Mar Negro que realizaram a série de publicações online intitulada, a saber:

\footnotetext{
${ }^{4}$ Os autores Andreas Mehl, Alexander Merhlayuk e Oleg Gabelko reúnem a produção de artigos de helenista e romanistas russo escritos em língua inglesa visando a construção do intercambio e o diálogo com os seus pares de IES no Ocidente.
} 
International Centre for Black Sea Studies ${ }^{5}$ (Danish National Research Foundation); Greek on the Black Sea: Ancient Art from the Hermitage 6 e The British Institute at Ankara responsável pelas pesquisas arqueológicas na região da Turquia e na região de Pichonari, Mar Negro 7 . Podemos afirmar que conhecemos bem o mar Egeu, os pesquisadores debateram sobre a questão do mediterrâneo e a relação com a população sediada em sua margem e agora, estamos navegando nas águas turvas e turbulentas do saber em direção ao Mar Negro. Para nós, helenistas e pesquisadores, a conectividade e o conhecimento sobre o espaço geográfico marítimo na região do Pontus Euxinus e a região de Colquida mantém-se em plena navegação.

\section{Fontes Antigas}

ARISTOPHANES. The Plays of Aristophanes. William Benton Publisher. London: Encyclopedia Britannica, 1952. Ed. bilíngue.

ARISTOTLE. Constitution d'Athènes. Trad. G. Mathie. Paris: Les Belles Lettres,1996.

. Politics. Trad. H. Rackham. Cambridge: The Loeb Classical Library, 1990. Ed. bilíngue.

HERODOTUS. History. Trad. A. D. Godley. London: Willian Heinemann, vol.1 (1990), vol. 2 (1995), vol. 3 (1994), vol. 4 (1981) - Ed. bilíngue.

PAUSANIAS. Description of Greece. Books I and II. Trad. W. H. S. Jones. Cambridge: Harvard University Press, 1992.

PLUTARCH. Biography. Bernadotte Perrin. Harvard University Press, 1989.

STRABON. Geographie. Tomes VI. Trad. Raoul Baladié. Paris: Les Belles Lettres, 1978.

THÉOPHRASTE. Characters. Paris: Les Belles Lettres, 1964.

5 O centro de pesquisa composto por arqueólogos e historiadores tem como site: http://www.pontos.dk/ no que estão disponibilizados artigos, livros e debates sobre a presença de gregos na região no período arcaico e clássico

6 O site tem como endereço: https://www.getty.edu/art/exhibitions/black_sea

7 The British Institute at Ankara mantem ativa as pesquisas arqueológicas na região da Turquia e na região de Pichvnari, Mar Negro, ver http://biaa.ac.uk/; http://biaa.ac.uk/research/item/name/pichvnari-excavations . 
THUCYDIDES. History of the Peloponnesian War. London: William Heinema. Vol. 1 (1991); vol. 2 (1998); vol. 3 (1992); vol. 4 (1976). Ed. bilíngue.

VELHO OLIGARCA. A Constituição dos Atenienses. Trad. Neyde Theml e André Chevitarese. Vitória: EDUFES, 2002.

XENOPHON. Hellenica. London: William Heinemann,vol.1 /2, 1985. . Memorabilia, Oeconomicus. London: William Heinemann, 1992

Anabasis IV. Trans.Carleton L. Brownson.London: The Loeb Classical Library,1930.

\section{Referências bibliográficas}

ANDREAU, Jean. "L'économie antique: présentation". Annales, 5, 1995, p. 947-960.

BERARD, Claude et ali. A City of Image: iconography and society in ancient Greece. Princeton: Princeton University Press,1989.

BOARDMAN, John. Greek Sculture: The Classical Period. London: Thames and Hudson, 1985.

BOTHMER, Dietrich von. Painted Greek Vases. The Metropolitan Museum of Art Bulletin, vol. 21, 1962. www.jstor.org/stable3258463 acesso em 23/11/2013.

BURSTEIN, Stanley M. The Greek Cities of the Black Sea.in: A Companion to the Classical Greek World. Oxford:Blackwell,2006, p.137-152.

CANDIDO, $\mathrm{M}^{\mathrm{a}}$ Regina. Atenas, liderança unipolar no Mar Egeu (480-411 a .C). Rio de Janeiro: Letras e Versos/ NEA-UERJ, 2016.

CANDIDO, Ma Regina. Medeia, Mito e Magia: A imagem através do tempo. $2^{\mathrm{a} e d . R i o ~ d e ~ J a n e i r o: ~ F a b r i c a ~ d e ~ L i v r o s / N E A / U E R J, ~} 2010$.

CANDIDO, $\mathrm{M}^{\mathrm{a}}$ Regina. Novas Perspectivas sobre aplicação metodológica em História Antiga. IN: Busca do Antigo. ROSA, Claudia Beltrão (eds). Rio de Janeiro: NAU, 2010, pp.13-23.

CARPENTER, Thomas H. T. Art and Myth in Ancient Greece. London: Thames and Hudson, 1985. 
CKONIA,A.M. A propos de I'exportation de l'or colchidien. Pont-Euxin et Polis?Polis hellenis et Polis Barbaron.Comtoises: Presses Université FrancheComtoises,2005, p.263-272.

COHEN, Beth. Not the Classical Ideal: Athens and Construction of the Other in Greek Art.Leiden: Brill, 2000.

CONSTANTAKOPOLOU, C.: The Dance of the Islands: Insularity, Networks, the Athenian Empire and the Aegean World. Oxford: Routledge. 2007.

COUPRIE, Dirk L.(org.) Anaximander in Context: new studies in origins of Greek Philosophy.New York: New York University Press, 2003.

COUPRIE, Dirk L. Heaven and Earth in Ancient Greek Cosmology: from Thales to Heraclides Ponticus. New York: Springer, 2011.

DANA, Madalina."Le Centre et la peripherie en question:deux concepts a revoir pour les disaporas", Pallas, 89, 2012mpp.57-76.

DIGGLE, James. On the Manuscripts and text of Eurípides: Medea. In: Classical Quarterly 33, p.339-357,Oxford: Oxford University Press,1983.

DOUMAS, C. What Didi the Argonauts seek in Colchis? Hermathena ${ }^{\circ}$ 150. Dublin: Trinity CollegeDublin, 1991.

DUECK, Daniela. Geography in Classical Antiguity. Cambridge: Cambridge University Press,2012.

FIGUEIRA, Thomas. Colonization in the Classical Period. Mnemosyne, Vol. II, Supplement 193, Leiden:Brill, 2008, pp.427-522.

FAUDOT, M.(eds). Pont-Euxin et Polis?Polis hellenis et Polis Barbaron.Comtoises: Presses Université Franche-Comtoises,2005.

FINLEY, Moses I. “The ancient city: from Fustel de Coulanges to Max Weber and beyond", in FINLEY, M. I. Economy and society in ancient Greece. Edited by Brent D. Shaw \& Richard P. Saller. Nova Iorque: Penguin Books, 1983, p. 3-23.

FINLEY, Moses. I. A Economia Antiga. Porto: Afrontamento, 1986.

GABRIELSEN,Vicent. The Black Sea in Antiguity. Oakville:Arhus University Press,2007. 
GILL,David W. J.Positivism, pots and long-distance trade.in. MORRIS,Ian (ed). Classical Greece: Ancient Histories and Modern Archaeologies. Cambridge:Cambridge University Press, 1994,pp.99-107.

HANSEN,Morgens Herman. Emporium:a study of the use and meaning of the term in the archaic and classical periods. In: Greek colonization:an account of Greek colonies and other settlements overseas. Leiden: Brill, 2006,p.1-39.

HOPMAN, Marianne. Revenge and Mythopoiesis in Euripides'Medea. In:Transactions of the American Philological Associations, 138 (2008)p.155183.

JOHNSTON,Sarah Iles. Medeia: essay on Medea in myth, literature, philosophy and art. Princeton: Princeton University Press, 1997.

KAKHIDZE, A., IASHVILI. I., Vickers, M. "Silver coins of Black Sea coastal cities from the fifth century BC necropolis at Pichvnari". Numismatic Chronicle 161, 2001, pp.282-288

KVIRKVELIA, Guram. Polis Barbaron in the Black Sea area in archaic and classical periods. Pont-Euxin et Polis?Polis hellenis et Polis Barbaron.Comtoises: Presses Université Franche-Comtoises,2005, p.33-40.

LUSCHIMIG,C.A.E. Granddaugher of Sun:A study of Euripides'Medea. Leiden:Brill, 2007.

MCDERMONTT, Emily A. Euripides'Medea:The Incarnation of Disorder. Pennylvania: The Pennsylvania State University Press,1989.

MEHL,Andreas (eds) Ruthenia Classica Aetatis Novae: A Collections of Words by Russian Scholars in Ancient Greek and Roman History. Stuttgart: Franz Steiner Verlag, 2013.

NOOMAN,Thomas S. The Grain Trade of the Northern Black Sea in Antiguity. The American Journal of Philosophy.vol.94, no 03, 1993, pp. 231-242.http://www.jstor.org. acessado em 10/02/2016.

NORA P. "História e Memória. Projeto História". Revista de Programa de Estudos Pós-Graduação em História e do Departamento de História da PUC-SP. São Paulo: PUCSP, 1981, p. 7-28.

PEBARTHE,Christophe. Emigres d'Athenes, Clerouques et Colons aux temps de la Domination Athenienne sur L'Egeu au V siecles a.C. in: Le Monde de L'Itinerance en Mediterranée de L'Antiquitw a L' Epoque Moderne. Paris:DE Boccard, 2009, pp.367-390. 
ROBERTSON, Martin. The Art of vase-painting in Classical Athens. Cambridge: Cambridge University Press,2000.

ROLLER, Duane W. Erastothenes' Geography.Princeton: Princeton University Press,2010.

TROFINOVA, Anna et J.Paul Getty Museum. Greek on the Black Sea: Ancient Art from the Hermitage. Los Angeles: Getty Publications, 2007.

TSETSKHLDZE, Gocha. Pichvnari and its environs. Paris:Universitaires Franc-Camtoise, 1999.

TSETSKHLDZE, Gocha. Greek Penetration of the Black Sea.in:The Archaeology of Greek Colonization. Oxford:Oxford University Press,2004, p.111-131.

VICKERS, M., Kakhidze, A.: 'The British-Georgian excavation at Pichvunari 1998: the 'Greek' and 'Colchian' cemeteries' Anatolian Studies 51, 2001, p. 65-90

VICKERS, M., Kakhidze, A. Pichvnari 1: Greeks and Colchians on the East Coast of the Black Sea: Results of Excavations Conducted by the Joint British-Georgian Expedition 1998-2002. Batumi.2004.

VLASSOPOULOS,Kostas. Greeks and Barbarians .Cambridge: Cambridge University Press,2013.

WYGANT,Amy. Medea, Magic and Modernity in France. Hampshire: Ashdate Publishing Limited, 2007. 